\title{
Policing Methamphetamine Problems: A Framework for Synthesising Expert Opinion and Evaluating Alternative Policy Options
}

MATTHEW MANNING School of Criminology and Criminal Justice, Griffith University

JANET RANSLEY School of Criminology and Criminal Justice, Griffith University

CHRISTINE SMITH Department of Accountancy, Finance and Economics, Griffith University

LORRAINE MAZEROLLE Institute for Social Science Research, University of Queensland

ALANA COOK School of Criminology and Criminal Justice, Griffith University

\begin{abstract}
Increasingly, governments and police agencies require evidence of effectiveness and efficiency with respect to law enforcement policies. The existing 'what works' literature, specifically on drug law enforcement, focuses mainly on the effectiveness question when making complex choices between drug policy alternatives, but fails when it comes to incorporating empirical evidence and the experience of key experts in the decision making process. In addition, little attempt has been made to employ sophisticated techniques to assist in complex policy decision-making with respect to funding competing policing policy alternatives. We use the methamphetamine problem in Australia to illustrate a way of evaluating, using multi-criteria analysis, alternative policy options for developing better drug policy.
\end{abstract}

Key words: Methamphetamine, Drug Policy, Economic Analysis, Analytical Hierarchy Process 


\section{Biographical Sketch}

\section{Matthew Manning}

Matthew Manning is an economist in the School of Criminology and Criminal Justice, Griffith University. Matthew has interests and experience in applied microeconomics, decision analysis, operations research, systematic and meta-analytic reviews and economic analysis techniques (e.g. cost-benefit analysis). Matthew's economic background has provided cross-disciplinary links with researchers and practitioners in the areas of criminology, psychology, special education, and operations research.

\section{Janet Ransley}

Janet Ransley is an Associate Professor and current Head of the School of Criminology and Criminal Justice at Griffith University. Her research interests include the governance of crime and policing, and the development, implementation and evaluation of criminal justice policy. She holds degrees in law and arts, a Masters in Public Administration and a PhD in law.

Janet is an associate investigator in the ARC Centre of Excellence in Policing and Security, and is an academic participant in the current Australasian Policing Forum Executive Sessions. She has authored over 30 books, book chapters and journal articles, and been an adviser to numerous government policy inquiries.

\section{Christine Smith}

Christine Smith is a Professor of Economics in the Griffith Business School. She is currently the Head of the Department of Accounting, Finance and Economics. Her areas of research interest include regional and urban economics, policy evaluation and conflict 
management. She holds a Bachelor of Economics and Master of Regional Science from University of Queensland and an MA and PhD from Cornell University. She sits on numerous journal editorial boards and has been a Chief Investigator on a number of crossdisciplinary Australian Research Council grants. She is the author or editor of numerous books, book chapters, journal articles and consulting reports.

\title{
Lorraine Mazerolle
}

Lorraine Mazerolle is a Research Professor in the Institute for Social Science Research (ISSR) at the University of Queensland where she leads a team of highly talented research scholars with expertise in experimental criminology, urban criminology, survey methods, advanced multi-level statistics and spatial statistics. She is the Foundation Director and a Chief Investigator in the Australian Research Council (ARC) Centre of Excellence in Policing and Security (CEPS) and a Chief Investigator in the Drug Policing Modelling Program. Professor Mazerolle is a Fellow of the Academy of Experimental Criminology, President of the Academy and author of numerous scholarly books and articles on policing and crime prevention.

\author{
Alana Cook \\ Alana Cook is a research assistant in the School of Criminology and Criminal Justice, \\ Griffith University. She holds a Bachelor of Forensic Science, Bachelor of Criminology \\ and Criminal Justice, and a Graduate Certificate in Crime Analysis from Griffith \\ University. She is currently doing her honours degree in Criminology looking at the \\ displacement effects of situational armed robbery prevention measures.
}




\section{Policing Methamphetamine Problems: A Framework for Evaluating Costs and Utility of Alternative Policy Approaches}

Recent years have seen enthusiastic adoption of the 'what works' paradigm in policing (see Sherman, 2009). But as the costs of law enforcement rise, especially in a tight fiscal environment, the question is being re-phrased as 'what works most costeffectively'. Increasingly, governments and their police agencies want to ensure that expenditure in law enforcement is being used both effectively, to achieve the desired outcomes, and is an efficient use of resources. Most of the existing 'what works' literature focuses predominantly on the effectiveness question, examining for example the impact of focused policing of hot spots (see Weisburd, 2005) or street level drug law enforcement (Mazerolle, Soole, \& Rombouts, 2006).

Police agencies have traditionally allocated resources and pursued interventions based on perceived priorities, operational demands and likelihood of success (Stockdale \& Whitehead, 2003). Multi-criteria analysis improves on this simplistic protocol by allowing decision-makers to employ a structured method for making informed choices about alternatives consistent with a range of criteria (Saaty, 2000). Policy can then be developed that incorporates measures of both effectiveness and efficiency (Manning, Homel, \& Smith, 2011).

Calls for more 'evidence-based' policy making often assume a straightforward transferral of scientific data into public policy. In fact, these data are only one component of the policy process, which must also take into account competing sources of information, values, the views of stakeholders and their political agendas (see Ritter, 2009) and the implementation process. This is particularly the case in law 
enforcement, where in many countries the political law and order agenda is the dominant policy paradigm (Edwards \& Sheptycki, 2009).

Despite this, the collection of all relevant data is, or should be, a crucial part of an informed policy process. However, much of the relevant literature focuses on evaluations of a particular policy option rather than on comparing multiple, competing options. This raises complex issues, including the best way to capture and weigh all the relevant data from a variety of sources and people. In this paper we apply a method that can assist policy makers in making complex policy decisions that incorporate both criteria. We do so by providing an applied microeconomics method that assesses strategies to reduce the effect of the methamphetamine problem in Australia. This method involves comparing five alternative policy options: (1) Project STOP - a third party policing initiative to address the problem of precursor diversion through Australian community pharmacies; (2) an outright ban on pseudoephedrinebased products sold in Australian pharmacies; (3) a prescription only model of products containing pseudoephedrine; (4) increased street-level policing responses; and (5) a do nothing option.

The overall research question is: among the alternatives available, which one has the most potential to moderate the usage of methamphetamine and minimise its associated harms? To answer this we apply a multi-criteria analysis method (Mendoza et al., 1999), namely the analytical hierarchy process (AHP) (Saaty, 1980). AHP provides a structured model for analysing the various components incorporated in a decision problem. AHP also assists in identifying how experts rate the relative effectiveness of different policy options (Saaty, 2000). This rating may not be the best evidence, in that the experts' views are subjective and based on incomplete knowledge, however, given the paucity of evidence on what works in drug law 
enforcement (as discussed further below) it is the best available evidence in the current environment. When more evidence does become available, Manning (2008) has adapted the AHP method to incorporate an objective component.

This paper is divided into five sections. We begin with a brief survey of the policy responses to methamphetamine problems in Australia, and the development of Project STOP as a third party policing intervention. Then we provide a brief summary of the AHP discussing the benefits and limitations of the method followed by an example of its application. Next, we discuss how we applied the AHP to assist in the development of better drug policy. Finally, we provide results briefly considering their implications.

\section{Policy Responses To The Methamphetamine Problem In Australia}

The costs of illicit drug problems in Australia in 2004-2005 were estimated to be around A $\$ 8.1$ billion (Collins \& Lapsley, 2008). This figure includes social and economic costs associated with illness, premature death, crime, reduced community amenity, accidents and lost productivity. Common illicit drugs used in Australia are cannabis, heroin and amphetamine-type stimulants, which includes the synthetically produced stimulant methamphetamine. A national survey found methamphetamine prevalence rates in the general community of 7 per cent, behind cannabis (35.4 per cent), ecstasy (10.3 per cent) and hallucinogens ( 8.8 per cent) in 2010 (Australian Institute of Health and Welfare, 2011). Although this represents a decline over earlier years, down from around 9 per cent in 2005 (Australian Institute of Health and Welfare, 2011), other evidence suggests associated harms to be increasing. Such evidence includes emergency hospital admissions and ambulance attendances attributed to methamphetamine use (Victorian Government, 2006). Possible 
explanations for the increase in reported harms include the increasing availability of more harmful forms of the drug, such as crystalline methamphetamine (or 'ice'), and increased use of injection (Adams et al., 2007).

Potential state responses to this problem fall into four main categories: prevention, such as education and community approaches; law enforcement, including source country programs, border interdiction and domestic policing approaches; treatment, aimed at getting users to reduce or cease their use; and harm reduction, to reduce harmful side effects of use, such as by needle exchange programs (Ritter \& McDonald, 2008). To a large extent, the Australian experience has been dictated by the international regulatory regime on illicit drugs, which has in turn been driven by the United States led 'war on drugs' (Bull, 2008). This environment favours law enforcement approaches to illicit drugs.

Australian governments' reliance on law enforcement responses is considerable, with around 56 per cent of total illicit drug expenditure spent on such interventions, 22 per cent on prevention, 19 per cent on treatment, and 2 per cent on harm reduction (Moore, 2008). Domestic law enforcement approaches typically include strategies such as undercover operations, crackdowns, drug-free zones, intensive street policing, raids, and drug driving test programs. More recent, innovative strategies include hotspot targeting, financial monitoring of suspects, precursor controls, and third party approaches (Mazerolle \& Ransley, 2006).

While as discussed earlier, the evidence suggests some changes in the demand for methamphetamine, there have also been changes in supply patterns. Supply comprises the importation, manufacture, trafficking and selling of the drug, as opposed to its consumption. In Australia the major source of methamphetamine is local production in clandestine laboratories (Australian Crime Commission, 2007), 
using precursor chemicals, principally pseudoephedrine, a component in cold and influenza medications. These precursors are obtained predominantly from local sources by diversion of legal products, principally cold and influenza medications bought from community pharmacies. A smaller proportion of the precursors are illegally imported.

In response to the misuse of these pharmaceuticals, the availability of licit precursors has become increasingly regulated in recent years. At the international level, the 1988 Convention against the illicit trafficking in narcotic drugs and psychotropic substances requires signatory states, such as Australia, to incorporate into domestic law measures against drug trafficking and the diversion of precursor chemicals. In Australia, the federal division of power has fragmented the response to this convention. The federal government has responsibility for customs, imports and border control; while the eight states and territories have power over most law enforcement, and pharmacy regulation. Significant measures addressing precursor diversion have occurred at both levels, including national level 'rescheduling' of pseudoephedrine-based products, meaning that they can only be sold at licensed pharmacies by a pharmacist, rather than being available 'across the counter'; and state-based tighter guidelines for the handling, storage, dispensing and sale of such products in pharmacies, along with increased criminal offences and penalties for diversion (Australian Crime Commission, 2007). These state-based guidelines and regulations have varied significantly across the different jurisdictions.

The new regulatory environment, at both state and federal level, has increased the compliance burden for pharmacists. They are now subject to detailed rules about what products they may stock, where in their stores they keep them and how, who may sell them and to whom, how they must be labelled, and what information must be 
kept regarding such sales. As a result of this compliance burden, the Queensland branch of the Pharmacy Guild of Australia and the Queensland Police Service developed Project STOP. Project STOP is a real-time online recording system which can show pharmacists a customer's recent sales history for pseudoephedrine-based products at other pharmacies in the same state. This assists pharmacists in deciding whether or not to proceed with suspect sales, as well as aiding their statutory recordkeeping and reporting obligations. Initially trialled in Queensland, the database was rolled-out throughout Australia as part of the National Strategy to Prevent the Diversion of Precursor Chemicals into Illicit Drug Manufacture, in late 2006 (Australian Crime Commission, 2006), although with marked differences between the states (see Ransley et al., 2011).

Most law enforcement responses to illicit drugs such as methamphetamine are largely reactive. They rely on after-the-event investigation and prosecution of people involved in diversion and manufacturing, using methods such as informants, undercover operations, crackdowns and raids (Mazerolle et al., 2006). By contrast, Project STOP has a preventive focus, aimed principally at preventing diversion from occurring in the first place by improving pharmacists' knowledge and ability to refuse suspect sales. Project STOP also involves pharmacists in drug law enforcement. It does this by requiring pharmacists to gather information and pass it on to police, with the Project Stop database providing the key technology for this to occur. This constitutes 'third party policing', by which some policing functions are undertaken by third parties using regulatory or civil law levers at their disposal (Mazerolle \& Ransley, 2006), especially as pharmacists face disciplinary or legal sanctions for not complying with the requirements of the scheme. This mandating of policing functions 
by third parties has also been extended to other bodies, such as chemical wholesalers and retailers (Cherney, O'Reilly, \& Grabosky, 2006).

Project STOP, therefore, represents a major expansion in law enforcement efforts directed at the problem of methamphetamines. It has imposed significant compliance costs on non-police burden bearers, especially pharmacists and their associations, and the health agencies that regulate them. In addition, it has resulted in extra burdens for the public who face hurdles in accessing medications needed for legitimate reasons. This has occurred with little evaluation of either the impact of Project STOP on the problem it seeks to address, or its economic effectiveness in doing so. This paper sets out a framework for evaluating such policy initiatives using the AHP method.

\section{The Need for Multi-Criteria Analysis}

The call for more evidence-based policy has furthered the agenda for multicriteria analysis (MCA), with economics/operations research seemingly able to provide the objective quantification of information that proponents argue should be the basis of all policy decisions (Neylan, 2008). Social sciences such as economics offer a promise of removing policy decisions from the messy world of contested values, politics and clashing stakeholders, to one of objective rationality. In law enforcement policy, where law and order agendas have been so prominent (Currie, 2007), the promise of 'scientification' has been particularly alluring. But critics, such as Neylan (2008), argue that all science involves unstated assumptions shaped by beliefs and values. Edwards and Sheptycki (2009) also question the possibility or desirability of scientifically detached research, and ask why should the 'contributory expertise' of social scientists be favoured over the views of other political and moral 
actors on questions that are inherently value-laden. They suggest instead that research knowledge should be assessed in context - the historical, political, cultural and economic conditions in which the particular problem is situated. Similarly, Head (2008) suggests a three-lens approach to evidence-based policy, in which research, political and practice-based sets of evidence should be incorporated. Multi-criteria analysis is a way of addressing such critiques of economic evaluations. Research data are an important first step towards a comprehensive understanding of the topic. However, by incorporating the views and experiences of expert practitioners via the AHP model, we can view the problem in a way that integrates the three lenses of research, practice and politics, and take account of different forms of expertise. Ideally, when new policies are introduced data would be collected in a systematic way allowing the effectiveness of these policies to be measured and compared in both absolute and relative terms. Often this is not the case and we have to, after implementation, use available information to indirectly estimate effectiveness. For example, one might be able to obtain data on factors relating to the methamphetamine problem (e.g., $\mathrm{X}, \mathrm{Y}$ and $\mathrm{Z}$; where: $\mathrm{X}=$ difficulty in accessing other drugs; $\mathrm{Y}=$ social factors contributing to dependency; and, $\mathrm{Z}=$ policing the methamphetamine problem (i.e. resource allocation decisions)) prior to implementation of an intervention and on those same factors (X, Y and Z) after implementation and seek to attribute the change in $\mathrm{X}, \mathrm{Y}$ and $\mathrm{Z}$ to the intervention - in effect conduct an interrupted time series analysis of the factors contributing to the methamphetamine problem. In short, an interrupted time series analysis is a quasiexperimental design where an ordered set of observations is analysed pre and post intervention. The causal hypothesis is that observations after the intervention will have a different level or slope from those before the intervention (Wei, 2006). 
Unfortunately many variables other than the intervention may be influencing the factors contributing to the methamphetamine problem - for example, changing demographics or changing economic conditions. As a result any time series analysis would need to be multivariate in nature and have a sufficient number of observations (see Wei, 2006 and Lucas, 1983) to allow for meaningful statistical tests of effectiveness to be performed. Often policies need to be evaluated before the required time series of observations could be observed. For a full review of the interrupted time series technique as applied in the social sciences see McDowall et al. (1980) and Yaffee and McGee (2000). As a result, other methods for performing such evaluations need to be identified. A second option would be to have a semi-experimental design incorporated in the implementation of the policy, with some sections of the population participating in the program and others not, and comparisons made with respect to the prevalence of the factors $(\mathrm{X}, \mathrm{Y}$ and $\mathrm{Z})$ in the control and non-control groups. This requires that the control and non-control groups be carefully selected so that they are comparable in terms of factors that might influence the prevalence of the $\mathrm{X}, \mathrm{Y}$ and $\mathrm{Z}$ factors independent of the policy. It also, arguably, involves ethical/moral issues in the determination of who should be subject to the policy and who should not.

An alternative approach, which could be explored, is to draw upon expert opinion such as that of experienced practitioners who have worked with the methamphetamine problem and the associated $\mathrm{X}, \mathrm{Y}$ and $\mathrm{Z}$ factors over an extended time period. This approach allows use of their subjective judgements regarding the relative effectiveness of proposed alternatives. While lacking a traditional 'scientific' basis, this approach draws on previously untapped practitioner and implementation expertise in an organised way. One version of such an approach is the analytical hierarchy process (AHP) procedure. This methodological framework, developed in 
the operation research/management science literature, serves as a set of tools specifically designed to deal with decision problems that involve complex conflicting criteria and objectives (Saaty, 1980). We use the term evaluation in this paper to be consistent with what is commonly coined 'multi-criteria evaluation problems' (Edwards \& Newman, 1982). Such problems often consist of a finite number of alternatives that are explicit in the beginning of the solution process. Applying the multi-criteria approach allows one to sort or classify these alternatives (Keeney \& Raiffa, 1976).

A number of multiple-criteria decision making (MCDM) techniques exist. Multiple-Goal Analysis (MGA) represents an evaluation of multiple goals, where the goals are expressed both quantitatively and quantitatively (Edwards \& Newman, 1982; Dodgson et al., 2001). For example, a MGA could evaluate three alternatives (e.g. alternatives $\mathrm{X}, \mathrm{Y}$ and Z) with respect to four explicit goals (e.g. efficiency represented in dollars, revenue expenditure impact in dollars, equity and impact on employees). MCA, on the other hand, compares alternatives (e.g. alternative paper towel brands $\mathrm{X}, \mathrm{Y}$ and $\mathrm{Z}$ ) with respect to typically one goal (e.g. increasing product desirability). Separate MCA's are conducted for each goal. In this form of analysis, the attributes of product desirability (e.g. softness, absorptiveness, price, size, design and integrity) could be compared with respect to the goal. Further, the analysis could be extended to compare the attributes with respect to different levels of intensity (e.g. high, medium, low) to provide priority rankings for the three alternatives (Saaty, 2001). MCA goes by other names including; multiple criteria weighting (Easton 1973), multi-attribute decision making (Edwards \& Newman, 1982), multiple objective analysis (Keeney \& Raiffa, 1976), and multi-criteria decision analysis (Joubert et al., 1997). 
Multi-criteria techniques have been successfully applied to many social, economic and environmental problems. Ballestero and Romero (1998) provide a summary of the various multi-criteria techniques and their application to economic problems. Romero and Rehman (2003) survey applications of MCDM as they apply to environmental problems. Saaty (2001) provides practical examples of MCA to social and economic issues including the future of higher education, projecting oil prices, transport predictions in the Sudan, the future of the steel industry and dealing with traffic congestion. With respect to illicit drug research, Nutt et al. (2007) explored the feasibility of a nine-category matrix of harm, with an expert Delphi procedure, to scientifically assess the harms of a range of illicit drugs. In addition, Nutt, King and Phillips (2010) used multi-criteria decision analysis to assess the harms caused by the misuse of drugs and rate twenty drugs on sixteen criteria to create a relative weighting with respect to their level of harm to individuals and others.

The origins of AHP in particular can be traced back to the 1970's (Saaty, 1977) where it was applied to solve difficult decisions regarding scarce resource allocation and planning needs for the military (Saaty, 1980). Since the 1980's, it has been applied in multiple contexts which range from the analysis of conflicts (e.g. Johannessen, Bandara \& Smith, 2004; Tarbell \& Saaty, 1980) in which attempts are made to identify and analyse potential political structures that may serve as a resolution to a conflict, to forming corporate strategies to bolster effective competition (Saaty, 1994), and the adoption of a model for analysing facility location selection decisions (Yang \& Lee, 1997). The method has also been employed in the health sector to assist in choosing the best hospice model to aid in caring for the terminally ill (Saaty, 1994), and has been extended to incorporate the analysis of future 
education in the USA (Alexander \& Saaty, 1977), and applications in finance (Saaty, 1990) and engineering (Triantaphyllou \& Mann, 1995).

\section{The Analytical Hierarchy Method in More Detail}

The AHP is a method to assist in making complex policy decisions in areas involving multiple criteria. The method assists in capturing subjective and objective information (see Manning et al., 2011) by identifying and weighting the criteria considered essential to these decisions. The method also provides a means of checking the consistency of the various weights employed thus reducing bias in the overall decision-making process (Manning, 2008; Saaty, 1994). While other multicriteria decision making methods could have been selected for use, these methods do not lend themselves readily to testing of key parameters using sensitivity analysis or checking for and correcting of results should participants selected for inclusion in the study generate inconsistent rankings of alternatives.

One of the other main benefits of the AHP is that it gives coherence to, and allows the ranking of, experts' knowledge about competing alternatives with multiple attributes. It is less useful in areas where knowledge is limited. It could be argued that knowledge about alternative law enforcement approaches to methamphetamines is such an area. However, this is not the case, particularly in Australia. The different state systems of regulation, along with a history of policy experimentation over the past ten years, has provided policy makers with sources of information and knowledge about the effects of different approaches. For example, in that period precursors have been rescheduled, law enforcement crackdowns have been experienced, and different states have taken at least three distinct approaches to regulating the way in which precursor medications can be sold (see Ransley et al., 
2011). We argue that experience in this arena is likely to provide some valuable insights worthy of being analysed via AHP, particularly given the paucity of other research evidence in the area.

The first step in AHP involves constructing a hierarchy, which serves as a tool to model a problem as it represents all the salient elements in relation to the problem (Figure 1).

\section{INSERT FIGURE 1 ABOUT HERE}

In its simplest form a hierarchy is comprised of a number of levels (Saaty, 2000). The top of the hierarchy identifies the goal. The next level down (Level 1) represents the key actors involved in the decision process (e.g., A, B, C, and D), below that level (Level 2) are the key objectives of each of the actors (e.g., $Q_{1}$ and $Q_{2}$ ); and, at the bottom of the hierarchy (Level 3) are the solutions or options available (e.g., $R_{1}, S_{1}$, and $T_{1}$ ). The size and complexity of the hierarchy may be considered unlimited as many more levels may be included should they prove necessary to fully analyse the problem. In addition, each criteria may include $x$ number of items salient to the given criteria.

The next step is to survey a group of experts (e.g. academics, practitioners, policy-makers) to attain their preferences for each of the criteria in the hierarchy. In short, the decision-maker judges the importance of each criterion in pair-wise comparisons (expressed by posing the questions "which of the indicators is more important?" and secondly, "by how much?"), which is expressed on a semantic scale of 1 (equality) to 9 (i.e. an indicator may be indicated as 9 times more important than the one to which it is being compared) (Table 1).

INSERT TABLE 1 ABOUT HERE 
This scale is employed to value judgments relating to all possible pairwise comparisons in a summary matrix $Q$ of dimension $n \times n$ (Table 2).

\section{INSERT TABLE 2 ABOUT HERE}

Depending on the complexity of the decision, and the number of levels present in the hierarchy, a number of such pairwise comparison matrices are developed. To illustrate this we use one matrix as an example. Table 3 provides a summary of judgments derived from Table 1 based on the objectives being compared. We use the reciprocal values of the upper diagonal to complete the matrix.

\section{INSERT TABLE 3 ABOUT HERE}

With a complete matrix (Table 3 ), we can then compute a normalised vector $\left(\mathrm{Q}^{*}\right)$ of priorities (or relative importance/s). To compute a normalised vector we begin by dividing the elements of each column of the matrix by the sum of that column.

Next, we add the elements in the rows. Finally, we divide this sum by the number of elements in the row (in this case 3 ) to produce a column vector of priorities $(0.2828,0.6434,0.0738)$. The sum of these elements is unity. The elements represented in Q* represent the respondent's relative weights or priorities for the objectives being compared. For example, Table 4 demonstrates that the respondent prefers objective $q_{2} 2.27(0.6434 / 0.2828)$ times more than $q_{1}$, and also prefers $q_{2}$ $8.72(0.6434 / 0.0738)$ times more than $q_{3}$.

\section{TABLE 4 ABOUT HERE}

We then need to check the consistency of our respondent's answers. This is often referred to as the measurement of intransitivity (Manning et al., 2011). A transitive ordering of preferences requires that if $X$ is preferred to $Y$, and $Y$ is preferred to $Z$, then $X$ is preferred to $Z$. This logic of transitivity is taken as an axiom of rationality with regards to preferences of individuals. A violation of transitivity 
implies an ambiguous ordering of alternatives or an intransitive ordering of preferences (Isard \& Smith, 1982; Manning et al., 2011).

Measuring the consistency of our respondent's answers requires firstly computing $\lambda$ max . $\lambda_{\max }$ is calculated from the sum of products between each element of the eigenvector (Table 4) and the sum of the columns of the reciprocal matrix (Table 3). Using our earlier example, $\lambda_{\max }=21 / 5(0.2828)+31 / 21(0.6434)$ $+13(0.0738)=3.0967$. Saaty $(1986)$ shows that a consistent reciprocal matrix is derived when the principal eigenvalue $\lambda$ max is equal to the order of the largest comparison matrix (i.e. $\lambda_{\max }=n$ ).

Next, we need to calculate a consistency index $(C I)$. $C I$ is a measure of the consistency of the pairwise comparisons, where

$$
C I=\frac{\lambda \max -n}{n-1}
$$

Using the above example, $C I=\frac{3.09673}{2}=0.048$

Calculating a consistency ratio $(C R)$, which assists us in determining the consistency of our respondent's answers, requires dividing $C I$ by a random consistency index $(R I)$. Saaty (1980) defines a random index $(R I)$ as '...the consistency index of a randomly generated reciprocal matrix from the scale 1 to 9 , with reciprocals forced' (p. 21). Thus:

$$
C R=\frac{C I}{R I}
$$

If the value of the $C R$ is smaller or equal to ten per cent then the level of inconsistency displayed by the respondent's answers is deemed acceptable. Levels greater than ten per cent indicate an intransitive ordering of preferences. Therefore, we need to go 
back to respondents and ask them to revise their pairwise comparisons to reduce this inconsistent ordering of preferences. Applying this to the above example,

$$
C R=\frac{G}{R I}=\frac{0.0484}{0.58}=8.3 \%<10 \%
$$

Given that $C R$ is less than ten per cent, based on a $3 \times 3$ matrix, we can conclude that our respondent's answers are within an acceptable range.

The final step is to test whether the ranking of alternatives is sensitive to key assumptions of the analysis (Levin \& McEwan, 2001). To conduct a sensitivity analysis one must firstly identify a key or group of key parameters. Generally, the key parameter is the importance weight that is assigned to each attribute. Consequently, it is important to gauge whether the ranking of alternatives change when alternative sets of weights are employed (Torrance, 1986). A full description of conducting a sensitivity analysis is available from Levin and McEwin (2001).

The above example represents the priorities of the elements on one level of a hierarchy with respect to one element of the next level. However, if there are more than two levels, the various priority vectors can be combined into priority matrices. This process would yield a final priority vector at the bottom of the matrix. A full example of such a model is provided in Manning (2008) and Manning, Homel and Smith (2011).

\section{Our AHP model}

The AHP model used in this study determines, among the alternatives available, the policy that will best assist in reducing the methamphetamine problem. This problem is represented hierarchically in Figure 2.

INSERT FIGURE 2 ABOUT HERE 
Level 1 of the hierarchy (see Figure 2) represents the potential factors or characteristics (as employed in this study) that contribute to the methamphetamine problem. The characteristics evaluated in this study were selected after consultation with experts from government (e.g. police), non-government organisations (e.g. drug outreach centres) and academics (e.g. researching and publishing in the area of health and criminology). They included:

(1) Social characteristics - The risk of an individual becoming involved in illicit drug abuse has been identified to increase upon exposure to certain genetic, biological, emotional, cognitive and social factors (Loxley, Toumbourou, \& Stockwell, 2004). Those factors which have been associated with a particularly high level of risk include experiences of sexual abuse, a history of family violence and neglect, incompletion of schooling, unemployment, relative poverty, lack of involvement in positive social networks, and exposure to parental drug abuse (Loxley et al., 2004).

(2) Environmental characteristics - In Australia, there exists a number of different drug markets and sub-populations of methamphetamine users (McKetin, McLaren, \& Kelly, 2005). Although there are numerous ways in which these sub-populations can be categorised, the analysis of usage patterns yields two general consumption environments. The first is the social consumption of methamphetamines (along with ecstasy) as a 'party drug'. In this context, methamphetamines are taken socially with friends prior to going out to bars/nightclubs (McKetin et al., 2005a). In contrast to this group there are those who engage in frequent methamphetamine use, often regarded as dependant. These individuals will often take the drug within their own home 
to achieve a feeling of euphoria prior to engaging in regular daily activities (e.g. household chores, going to work, relaxing) (McKetin et al., 2005a).

(3) Market characteristics - There is evidence that users are responsive to the availability and price of illicit drugs, and can switch or substitute drugs if necessary (Chalmers, Bradford, \& Jones, 2010; Dave, 2006; Saffer \& Chaloupka, 1999; Weatherburn et al., 2003). For example, Australia's 'heroin drought' in the 1990's coincided with a sharp increase in methamphetamine use. The possibility of methamphetamine users' seeking out alternate drugs if other opportunities are blocked within the current Australian context is seen through recent evidence presented by Mcketin et al. (2005a). The authors found that users of methamphetamine also had very high levels of polydrug use with at least one in five survey respondents also identified as a dependent heroin user.

(4) Consumption characteristics - The extent to which users can become dependent on methamphetamines is related to the method of consumption; with evidence that injecting and snorting of the drug are more problematic, compared to oral ingestion (Ross, 2007). Different types of methamphetamines can also be more problematic than others, with evidence that 'ice' or crystalline methamphetamine is particularly problematic (McKetin et al., 2005a). This association between a user's consumption habits and dependency is well established (McKetin et al., 2005a; McKetin et al., 2005b). Evidence shows that those individuals who reported injection as their favoured route of administration were far more likely to be dependent on the drug than those who reported swallowing or snorting of the drug. Further, people who took methamphetamine in the form of ice were twice more likely 
to be a dependant user than those who consumed the drug in other forms (McKetin et al., 2005a).

Level 2 of the hierarchy (see Figure 2) represent four possible methods of addressing the methamphetamine problem:

(1) Enforcement - Law enforcement interventions are aimed at the detection, prosecution or prevention of illegal activities. In the context of the diversion of legal pseudoephedrine into illicit methamphetamine, this includes reactive policing strategies such as crackdowns, laboratory detections and frontline policing, along with the monitoring of other potential points of supply in the wholesale and distribution chain, and interdiction of imports.

(2) Harm reduction - Harm reduction interventions are aimed at reducing the physical, psychological, social and economic harms associated with illicit drug use. They are often environmental strategies, for example, aimed at reducing unsafe user places and practices such as injection and snorting which have higher risks.

(3) Treatment - Treatment interventions are aimed at individuals and populations identified as problematic, and focus on rehabilitative strategies along with the treatment of any physical and psychological harms caused by their drug use.

(4) Prevention - Prevention interventions are aimed at inhibiting the take-up of drug use in the first place. Most common strategies include education and marketing campaigns.

Level 3 provides five alternative policies that may reduce the methamphetamine problem (see Figure 2). These include:

(1) Project STOP - Project Stop is a real-time web-based program for recording details from retail pharmacies of requests for legal pseudoephedrine products 
(used illegally for diversion into methamphetamine). It acts as a decisionmaking aid for pharmacists in fulfilling their legal obligation to ensure such products are sold only for a genuine therapeutic purpose. In Queensland, it also serves to record identifying details of all sales and non-sales. The database is available to all other pharmacy members to aid their decisionmaking, but also to police who use it as a source of intelligence for crime detection and prevention purposes.

(2) Outright ban - An outright ban on pseudoephedrine products would prohibit their production, distribution or sale for both licit and illicit purposes. Substitutes such as phenylephrine would be required for therapeutic use, although for some conditions their therapeutic value is less.

(3) Prescription only - Making pseudoephedrine products available only on the prescription of a medical practitioner would remove all discretion from pharmacists. Instead, doctors would assess the therapeutic need for such products and patients requiring pseudoephedrine would need to visit a doctor first.

(4) Increased reactive policing - Police strategies to detect and deter the diversion of pseudoephedrine products into illicit methamphetamines include crackdowns on users and suppliers, clandestine laboratory detections, and more frontline policing such as random and targeted patrols, particularly in known hotspots such as clubs and bars. An increase in such strategies would be aimed at detecting pseudoephedrine after the pseudo-runners have acquired it from community pharmacies.

(5) Do nothing model - This model would involve having unrestricted access to pseudoephedrine within community pharmacies. An example of this type of 
scenario is the decriminalization of cannabis within select parts of the USA, Portugal and other jurisdictions.

Respondents for this pilot AHP survey were selected on the basis of: (a) their ability to make decisions regarding methamphetamine policy; and/or (b) their demonstrated expertise and experience in evaluation of the efficacy of methods for reducing the methamphetamine problem in Australia. The selected participants came from three stakeholder groups: government officers (e.g. Police, Queensland Government and New South Wales Government officials); non-government organisations (e.g. drug treatment facilities and drug outreach centres); and academics expert in drug policy research and development. None of the respondents selected were involved in the development of Project Stop. The number of respondents selected was proportional to the size of the different stakeholder groups - with larger groups having more respondents. Recruitment of respondents was in accordance with an approved human research ethics protocol and an expert reference group guided their selection. None of the respondents were involved in the original conception of the Project STOP intervention, and none have been involved either in its ongoing implementation. This was a deliberate choice by the authors in order to reduce the problem of selection bias and/or accusations that the results represented a selffulfilling outcome.

\section{Results}

Results demonstrate that the experts surveyed consider Project STOP the highest priority (i.e. preference) among the policy alternatives with respect to reducing the methamphetamine problem with a priority rating of 0.438 . Other policy options, in order of perceived priority (or preference) for the goal of reducing the 
methamphetamine problem are prescription only (0.223), an outright ban on pseudoephedrine-based products sold in pharmacies (0.194), increasing reactive policing (0.079) and a do nothing model (0.066) (see Table 5).

There were no significant differences in rankings by respondents associated with the various stakeholder groups. This was confirmed by conducting an analysis of variance analysis (ANOVA) to determine if there was a significant difference between the mean rankings of the three different groups across the five different policy options. The ANOVA assumptions of normality and homogeneity were not violated for any of these options and the F values ranged from .354 (with a p value of .708 ) to .996 (with a p value of .393).

\section{INSERT TABLE 5 ABOUT HERE}

Experts considered consumption characteristics to be the most important characteristic with respect to reducing the methamphetamine problem $(0.362)$, followed in order of priority (or preference) by environmental characteristics (0.248), market characteristics (0.240) and social characteristics (0.15) (Table 6).

\section{INSERT TABLE 6 ABOUT HERE}

Figure 3 combines the results of the priority rankings. The vector of priorities derived from factors or characteristics that potentially contribute to the methamphetamine problem (social, environmental, market, consumption characteristics) are provided on the $X$-axis (schematically represented by vertical bars). The overall outcome percentage is provided on the left hand $Y$-axis, which ranges from .00 to .90 . Policy alternatives (project STOP, prescription only, outright ban, increased reactive policing and do nothing) are provided on the right hand $Y$-axis, 
together with the alternative priority percentage, which ranges from .00 to .50 . Overall rankings of program alternatives can be read from the right hand $Y$-axis. The five lines represent the overall contribution made by the outcomes, in terms of their percentage of priority, to each policy alternative.

\section{INSERT FIGURE 3 ABOUT HERE}

Focusing first on the left hand Y-axis, Figure 3 demonstrates that the policy alternative project STOP rates the highest (43.8\%) with respect to overall priority percentage rankings or perceived utility when considering, among the alternatives, the best alternative for reducing the methamphetamine problem. This is followed in order of percentage priority by the alternatives prescription only $(22.3 \%)$, outright ban (19.4\%), increased reactive policing (7.9\%), and 'do nothing' (6.6\%). Looking next at the vertical bars, the characteristic 'consumption' is rated the highest with respect to its contribution to the methamphetamine problem (36.2\% of total priority), followed in order of priority by the characteristics 'environmental' (24.8\%), 'market' (24\%), and 'social' (15\%). Furthermore, Figure 3 allows us to identify what characteristics contributed the most to the percentage priority rankings of the five policy alternatives - this is represented by the five lines showing the overall contribution made by characteristics, in terms of their percentage of priority, to each policy alternative. The lower four lines demonstrate a large gap between the characteristics 'environmental', 'market', and 'consumption', whereby the uppermost line (representing project STOP) lies significantly above the other lines by a large margin. This shows us that project STOP received large priority percentage ratings with respect to environmental, market and consumption characteristics, but not social characteristics. In contrast, we can see little variation with respect to the policy alternatives 'increased reactive 
policing and 'do nothing', and also 'prescription only' and 'outright ban' when considering the priority ratings regarding all characteristics.

The level of inconsistency for the hierarchy is 0.09 , which falls within the acceptable range. This result shows that choices made by respondents were overall relatively consistent. This value is important as it suggests that respondents collectively generated a transitive social ordering of preferences.

A sensitivity analysis was conducted to measure the responsiveness of the results to changes in the relative importance of characteristics contributing to the methamphetamine problem. Figure 4 shows results for 'social characteristics', whereby for there to be a change in overall priority rankings for the policy alternatives 'project STOP' and 'prescription only', respondents need to significantly change their ordering of preferences on this particular characteristic. The swapping of policy alternative preferences occurs at the intersection of the lines that represent 'project STOP' and 'prescription only' in Figure 4. The sensitivity analyses for the other three characteristics demonstrate similar results where respondents would need to significantly alter their ratings of perceived priority with respect to their contribution to the methamphetamine problem.

The illustrative example of the AHP method employed in this paper does not permit an analysis of the statistical uncertainty associated with our results. While standard deviations associated with our overall priority rakings could be calculated a detailed analysis of such statistics is beyond the scope of the current paper which is already very lengthy. Such analysis will be explored in subsequent papers when the pilot survey is expanded in size and scope since this is possible using the Expert Choice software used for deriving the results reported in this paper. 


\section{INSERT FIGURE 4 ABOUT HERE}

Two main findings emerge from these results. The first is that experienced drug law enforcement policy makers and practitioners agree on viewing Project STOP as the most effective policy option of the five alternatives offered. This was strongly the case across the dimensions of consumption, market and environment, and less strongly when considering the social factors contributing to illicit methamphetamine use. We reiterate that we do not argue these results amount to proof of effectiveness; but that by drawing the views of experienced practitioners into the evaluative mix we provide a richer and more informed assessment of policy-making in the area.

The second important finding is that increased policing is almost uniformly seen by experienced practitioners as only marginally better than doing nothing, when compared with the other policy options (Project STOP, prescription only, outright ban). This finding casts doubt on the reliance of Australian governments on law enforcement as the most prevalent and best-resourced approach to reducing drug problems. Our research suggests experienced practitioners and policy makers in the field see little value in increased law enforcement approaches, favouring instead a shift to more regulatory schemes. This finding has important implications for policy making.

As with all methods of policy evaluation there are weaknesses associated with the AHP approach which include the issue of rank reversal and hierarchy composition, the axiomatic foundations of the approach, the degree of ambiguity in the questions asked of the respondents, possible selection bias around choice of respondents, the scale used to measure the intensity of preferences. For a detailed outline of these weaknesses see Manning (2008), McCaffrey (2005), Harker and Vargas (1987), ((1986), and Warren (2004). 


\section{Conclusion}

Methamphetamine problems are a significant policy issue in Australia, as in many other countries. Governments overwhelmingly favour law enforcement responses to these problems, at the expense of diverting resources to other types of options, such as prevention, treatment or harm reduction. Increasingly, there is a need to establish that these resources have been well spent - that the law enforcement options pursued are both effective, in terms of achieving their objectives, but also represent the most efficient way of doing so. Good policy, we argue, should be based on the empirical evidence and also on the opinions of experts who contribute to policy making in this area. This raises complex issues, including the best way to capture and weigh all the relevant data from a variety of sources and people.

In this paper, we accomplished the goal of capturing and weighing all the relevant data from a variety of sources and experts using multi-criteria analysis; namely the analytical hierarchy process. In our study, we developed a hierarchy with the goal of identifying the best policy alternative (project STOP, outright ban, prescription only, increased reactive policing and do nothing) that could potentially reduce the methamphetamine problem. The hierarchy was made up of another 2 levels that incorporated four characteristics (i.e. consumption, market, environmental and social) and four possible methods (i.e. enforcement, harm reduction, treatment and prevention) for addressing the methamphetamine problem. Our results, which were drawn from a survey of experts from Queensland, Australia, reveal that 'Project STOP' is the most preferred option with respect to dealing with the methamphetamine problem followed in order of preference by 'prescription only', and an 'outright ban' 
on pseudoephedrine-based products sold in pharmacies. The options 'increased reactive policing strategies' and 'do nothing' proved to be the least favoured options.

From these findings we concluded that there is strong support from experienced practitioners and policy makers for more regulatory approaches aimed at prevention of illicit methamphetamine problems, and surprisingly little support, across a range of dimensions, for increased policing as the strategy of choice. These findings are not reflected in the current drug policy and political debate in Australia. However they are consistent with a notion that exploring various pathways to prevention of crime related problems represent a more cost effective manner of dealing with these problems rather than waiting until these problems become entrenched as a way of life for a large segment of the population - since the latter would necessitate a large diversion of police manpower to address not just the drug offence itself but also the other ancillary offences commonly associated with supporting a drug habit and/or offences committed while under the influence of this habit (National Crime Prevention, 1999).

Other authors have used multi-criteria approaches to the analysis of drug related problems and have used expert opinion in this analysis. For example Nutt et al. (2010) used key players, experts and specialists to help reveal the relative ranking of a range of drug harms in the United Kingdom. Our paper differs from previous studies in this area in that we focus explicitly on the use of multi-criteria analysis in policy evaluation or choice and conceive of the problem as one that can be disaggregated into a number of different hierarchical levels in order to assist in deriving a relative ranking of overall policy options.

While our methodology has the obvious limitation that the results derived from it are heavily dependent upon, and can be influenced significantly by, the choice 
of the group of experts selected to provide us with responses to our AHP questions, we adopt a range of strategies to minimise these drawbacks. In particular we cast our net for the selection of experts widely, we involve a steering group or expert panel to oversee our selection, we obtain our responses from selected experts in strict accordance with an approved human ethics protocol and we conduct a detailed sensitivity analysis of our results to ensure they are not unduly influenced by the responses of particular individual experts. Nevertheless as Project STOP is a national intervention, and the pilot study reported in this paper only includes respondents from one state within this nation, the authors plan a more extensive nationwide survey in the future to further address this potential source of criticism. We also plan to flesh out further some of the other policy options used as comparators for Project STOP within this survey.

Our current study focusses on the supply side of the illicit drug market, and in particular the relative effectiveness of various policy approaches aimed at reducing this supply (by reducing the availability of precursor inputs to their production). However, the analytical hierarchy method could usefully be employed to analyse the relative merits of alternative policy approaches that could be (or are currently being) used to reduce the demand for illicit drugs. This method also has a strong potential to be applied in the evaluation of proposed solutions beyond the field of illicit drug policy, thus further enhancing the usefulness of our results in working to provide clear guidance for policy makers. 


\section{Reference List}

Adams, K., Sandy, L., Smith, L., \& Triglone, B. (2007). Drug use monitoring in Australia: 2007 annual report on drug use among police detainees. Canberra: Australian Institute of Criminology.

Alexander, J., \& Saaty, T. (1977). Stability analysis of the forward and backward process of conflict analysis. Behavioural Science, 22, 375-382.

Australian Crime Commission. (2006). Illicit Drug Data Report 2005-06. Canberra: Australian Crime Commission.

Australian Crime Commission. (2007). Illicit drug data report 2006-07. Canberra: Australian Crime Commission.

Australian Institute of Health and Welfare. (2011). 2010 National drug strategy household survey report. Canberra: Australian Institute of Health and Welfare.

Ballestero, E., \& Romero, C. (1998). Multiple criteria decision making and its applications to economic problems. Boston: Kluwer Academic Publishers.

Bull, M. (2008). Governing the heroin trade: From treaties to treatment. Aldershot: Ashgate.

Chalmers, J., Bradford, D., \& Jones, C. (2010). The effect of methamphetamine and heroin price on polydrug use: A behavioural economic analysis in Sydney, Australia. International Journal of Drug Policy, 21(5), 381-389.

Cherney, A., O'Reilly, J., \& Grabosky, P. (2006). Networks and meta-regulation: Strategies aimed at governing illicit synthetic drugs. Policing and Society: An International Journal of Research and Policy, 16(4), 370-385.

Collins, D., \& Lapsley, J. (2008). The costs of tobacco, alcohol and illicit drug abuse to Australian society in 2004/05. Canberra: Commonwealth Department of Health and Aging. 
Currie, E. (2007). Against marginality: Arguments for a public criminology. Theoretical Criminology, 11(2), 175-190.

Dave, D. (2006). The effects of cocaine and heroin prices on drug-related emergency department visits. Journal of Health Economics, 25(2), 311-333.

Dodgson, J., Spackman, M., Pearman, A., \& Phillips, L. (2001). Multi-criteria analysis: A manual. London: Department of the Environment, Transport and the Regions.

Easton, A. (1973). Complex managerial decisions involving multiple objectives. New York: John Wiley \& Sons.

Edwards, W., \& Newman, J. (1982). Multiattribute evaluation. Beverly Hills: Sage Publications.

Edwards, A., \& Sheptycki, J. (2009). Third wave criminology. Criminology and Criminal Justice, 9(3), 379-397.

Head, B. (2008). Three lenses of evidence-based policy. Australian Journal of Public Administration, 67(1), 1-11.

Isard, W., \& Smith, C. (1982). Conflict analysis and practical conflict management: An introduction to peace science. Cambridge: Ballinger Publishing Company.

Johannessen, P., Bandara, J., \& Smith, C. (2004). An analysis of the Sri Lankan conflict using an economic tool. Economic Analysis and Policy, 33(2), 163188.

Joubert, A., Leiman, A., de Klerk, H., Katua, S., \& Coenrad Aggenbach, J. (1997). Fynbos (fine bush) vegetation and the supply of water: a comparison of multicriteria decision analysis and cost-benefit analysis. Ecological Economics, 22(2), 123-140. 
Keeney, R., \& Raiffa, H. (1976). Decisions with multiple objectives: preferences and value trade-offs. New York: John Wiley \& Sons.

Levin, H., \& McEwan, P. (2001). Cost-effectiveness analysis ( $2^{\text {nd }}$ ed.). London: Sage Publications.

Loxley, W., Toumbourou, J., \& Stockwell, T. (2004). The prevention of substance use, risk and harm in Australia: A review of the evidence. Canberra: Australian Department of Health and Ageing.

Lucas, R. (1983). Econometric policy evaluation: A critique. In K. Brunner and A. Meltzer (Eds.). Theory, policy, institutions: Papers from the CarnegieRochester Conference series on public policy. Amsterdam: Elsevier Publishing Company.

McCaffrey, J. (2005). Tests run: The analytical hierarchy process. MSDN Magazine.

McDowall, D., McCleary, R., Meidinger, E., \& Hay, R. (1980). Interrupted time series analysis. London: Sage Publications.

Manning, M. (2008). Economic evaluation of the effects of early childhood intervention on adolescent outcomes. $\mathrm{PhD}$, Griffith University, Brisbane.

Manning, M., Homel, R., \& Smith, C. (2011). An economic method for formulating better policies for positive child development. Australian Review of Public Affairs, 10(1), 61-77.

Mazerolle, L., \& Ransley, J. (2006). Third party policing. New York: Cambridge University Press.

Mazerolle, L., Soole, D., \& Rombouts, S. (2006). Street-level drug law enforcement: A meta-analytic review. Journal of Experimental Criminology, 2(4), 409-435. 
McKetin, R., McLaren, J., \& Kelly, E. (2005a). The Sydney methamphetamine market: Patterns of supply, use, personal harms and social consequences. Sydney: National Drug Law Enforcement Research Fund.

McKetin, R., McLaren, J., Kelly, E., Hall, W., \& Hickman, M. (2005b). Estimating the number of regular and dependent methamphetamine users in Australia Technical report. Sydney: National Drug Law Enforcement Research Fund.

Mendoza, G., Macoun, P., Prabhu, R., Sukadri, D., Purnomo, H., \& Hartanto, H. (1999). Guidelines for applying multi-criteria analysis to the assessment of criteria and indicators. Jakarta: Center for International Forestry Research.

Moore, T. (2008). The size and mix of government spending on illicit drug policy in Australia. Drug and Alcohol Review, 27(4), 404-413.

National Crime Prevention (1999). Pathways to prevention: Developmental and early intervention approaches to crime in Australia. National Crime Prevention, Canberra: Attorney-General's Department.

Neylan, J. (2008). Social policy and the authority of evidence. Australian Journal of Public Administration, 67(1), 12-19.

Nutt, D., King, L., \& Phillips, L. (2010). Drug harms in the UK: A multicriteria decision analysis. Lancet, 376(9752), 1558-1565.

Nutt, D., King, L., Saulsbury, W., \& Blakemore, C. (2007). Development of a rational scale to assess the harm of drugs of potential misuse. Lancet, 369(9566), 1047-1053.

Ransley, J., Mazerolle, L., Manning, M., McGuffog, I., Drew, J., \& Webster, J. (2011). Reducing the methamphetamine problem in Australia: Evaluating innovative partnerships between police, pharmacists and other third parties. Canberra: National Drug Law Enforcement Research Fund. 
Ritter, A. (2009). How do drug policy makers access research evidence. International Journal of Drug Policy, 20(1), 70-75.

Ritter, A., \& McDonald, D. (2008). Illicit drug policy: Scoping the interventions and taxonomies. Drugs: Education, Prevention, and Policy, 15(1), 15-35.

Romero, C., \& Rehman, T. (2003). Multiple Criteria Analysis for Agricultural Decisions. Amsterdam: Elsevier.

Ross, J. (2007). Illicit drug use in Australia: Epidemiology, use patterns and associated harm. Canberra: Australian Department of Health and Ageing.

Saaty, T. (1977). A scaling method for priorities in hierarchical structures. Journal of Mathematical Psychology, 15, 234-281.

Saaty, T. (1980). The analytic hierarchy process. New York: McGraw-Hill.

Saaty, T. (1986). Axiomatic foundation of the analytic hierarchy process.

Management Science, 32(7), 841-855.

Saaty, T. (1990). Multicriteria decision making: The Analytical Hierarchy Process. Pittsburgh, USA: RWS Publications.

Saaty, T. (1994). "How to make a decision: the analytic hierarchy process". Interfaces, 24(6), 19-43.

Saaty, T. (2000). Fundamentals of decision making and priority theory (2nd ed.). Pittsburgh: RWS Publications.

Saaty, T. (2001). Decision making for leaders: The analytic hierarchy process for decisions in a complex world. Pittsburgh : RWS Publications.

Saffer, H., \& Chaloupka, F. (1999). The demand for illicit drugs. Economic Inquiry, $37(3), 401-411$.

Sherman, L. (2009). Evidence and liberty: The promise of experimental criminology. Criminology and Criminal Justice, 9(1), 5-28. 
Stockdale, J., \& Whitehead, C. (2003). Assessing cost-effectiveness. In K. Bullock \& N. Tilley (Eds.), Crime reduction and problem-oriented policing (pp. 217251). Cullompton: Willan Publishing.

Torrance, G. (1986). Measurement of health state utilities for economic appraisal. Journal of Health Economics, 5(1), 1-30.

Triantaphyllou, E., \& Mann, S. (1995). Using the analytical hierarchy process for decision making in engineering applications: Some challenges. International Journl of Industrial Engineering: Applications and Practice,2(1), 35-44.

Victorian Government. (2006). Summary of key findings - Victorian drug statistics handbook 2006. Melbourne: Victorian Department of Health.

Warren, L. (2004). Uncertainties in the Analytic Hierarchy Process. South Australia: Defense Science and Technology Organisation.

Wei, W. (2006). Time series analysis: Univariate and multivariate methods ( $\left.2^{\text {nd }} \mathrm{ed}.\right)$. Boston: Pearson Addison Wesley.

Weatherburn, D., Jones, C., Freeman, K., \& Makkai, T. (2003). Supply control and harm reduction: Lessons from the Australian heroin drought. Addiction, 98(1), 83-91.

Weisburd, D. (2005). Hot spots policing experiments and criminal justice research: Lessons from the field. The Annals of the American Academy of Political and Social Science, 599(1), 220-245.

Yaffee, R., \& McGee, M. (2000). Introduction to time series analysis and forecasting with applications of SAS and SPSS. London: Academic Press.

Yang, J., \& Lee, H. (1997). An AHP decision model for facility location selection. Facilities, 15(9/10), 241-254. 
DR MATTHEW MANNING

School of Criminology and Criminal Justice

Griffith University

Mt Gravatt, Queensland

Australia

Tel.: +61 737355617

Fax: +61 737355608

Email: m.manning@griffith.edu.au

ASSOC PROF JANET RANSLEY

School of Criminology and Criminal Justice

Griffith University

Mt Gravatt, Queensland

Australia

Tel.: +61 737355612

Fax: +61 737355608

Email: j.ransley@griffith.edu.au

\section{PROF CHRISTINE SMITH}

Department of Accountancy, Finance and Economics

Griffith University

Nathan, Queensland,

Australia

Tel.: +61 737357670

Fax: +61 737353719

Email: christine.smith@griffith.edu.au 
PROF LORRAINE MAZEROLLE

Institute for Social Science Research

The University of Queensland

St Lucia, Queensland

Australia

Tel.: +61 737357670

Fax: +61 737353719

Email:1.mazerolle@uq.edu.au

\section{ALANA COOK}

School of Criminology and Criminal Justice

Griffith University

Mt Gravatt, Queensland

Australia

Tel.: +61 737355617

Fax: +61 737355608

Email: alana.cook@griffith.edu.au 
Fig. 1: An illustrative hierarchy

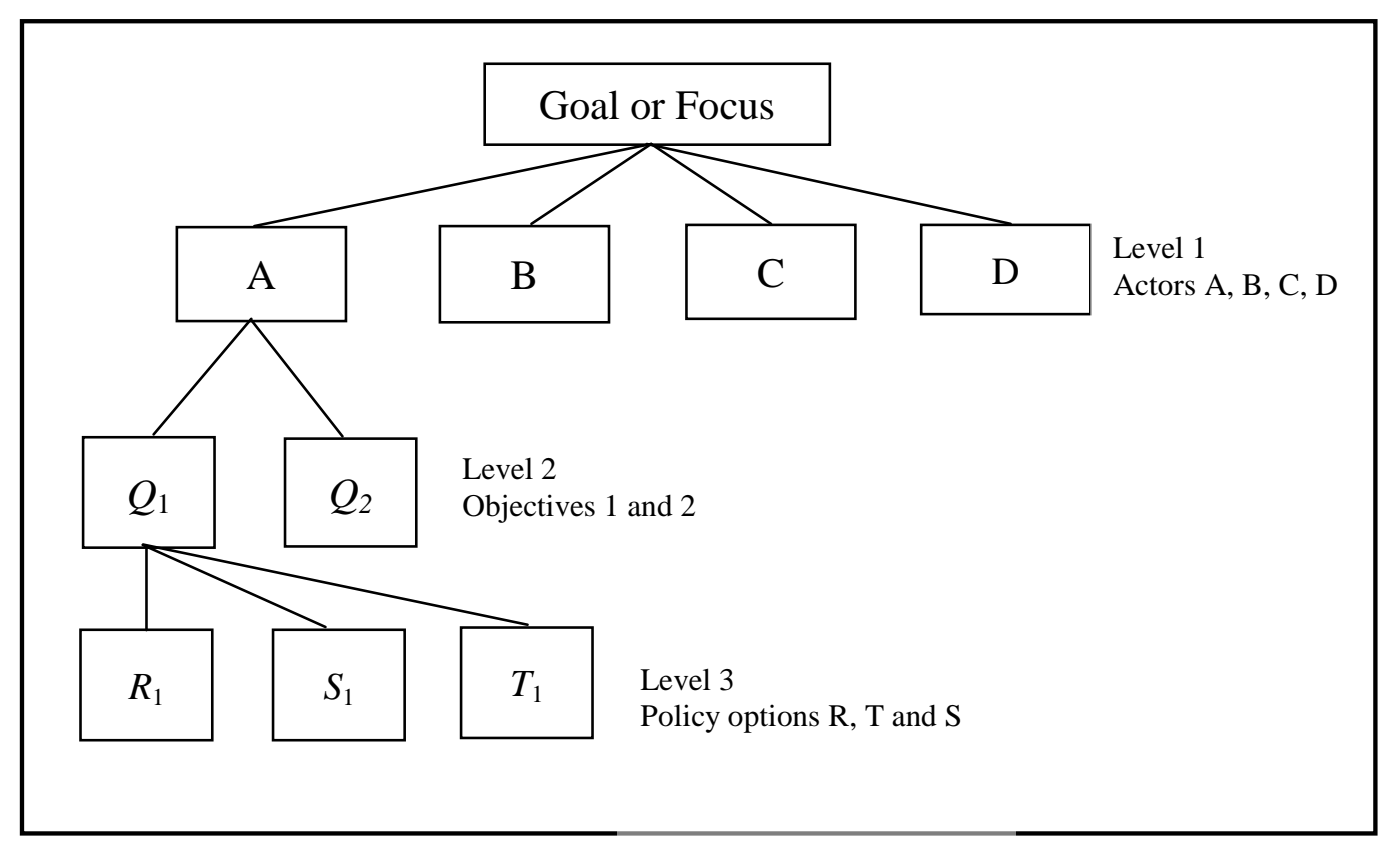

Source: Manning (2008) 
Figure 2: Methamphetamine AHP model

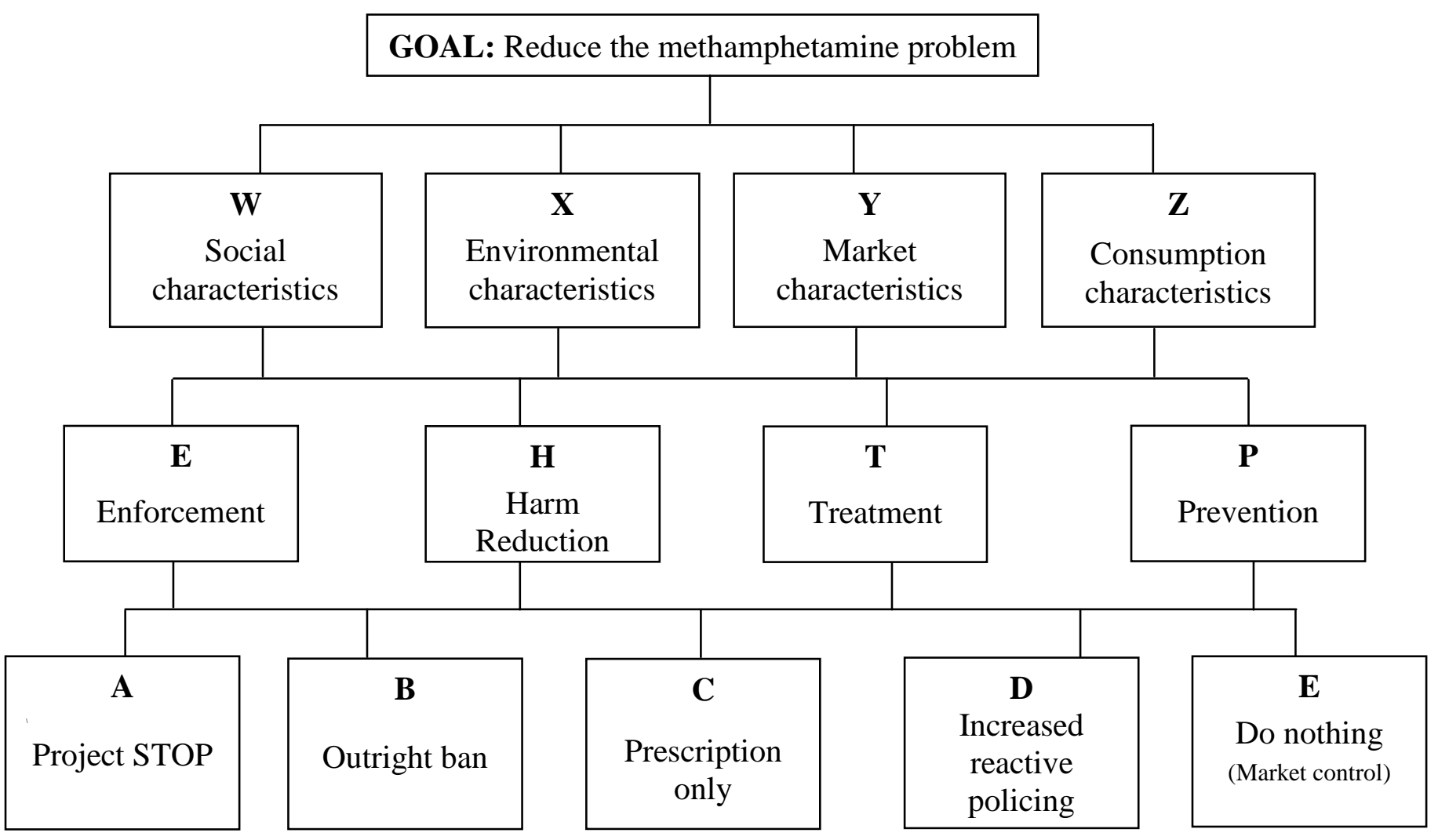

Where;

Level 1 = Factors

Level 2 = Characteristics of interventions

Level 3 = Solutions or options available 
Figure 3: Combined results of priority rankings

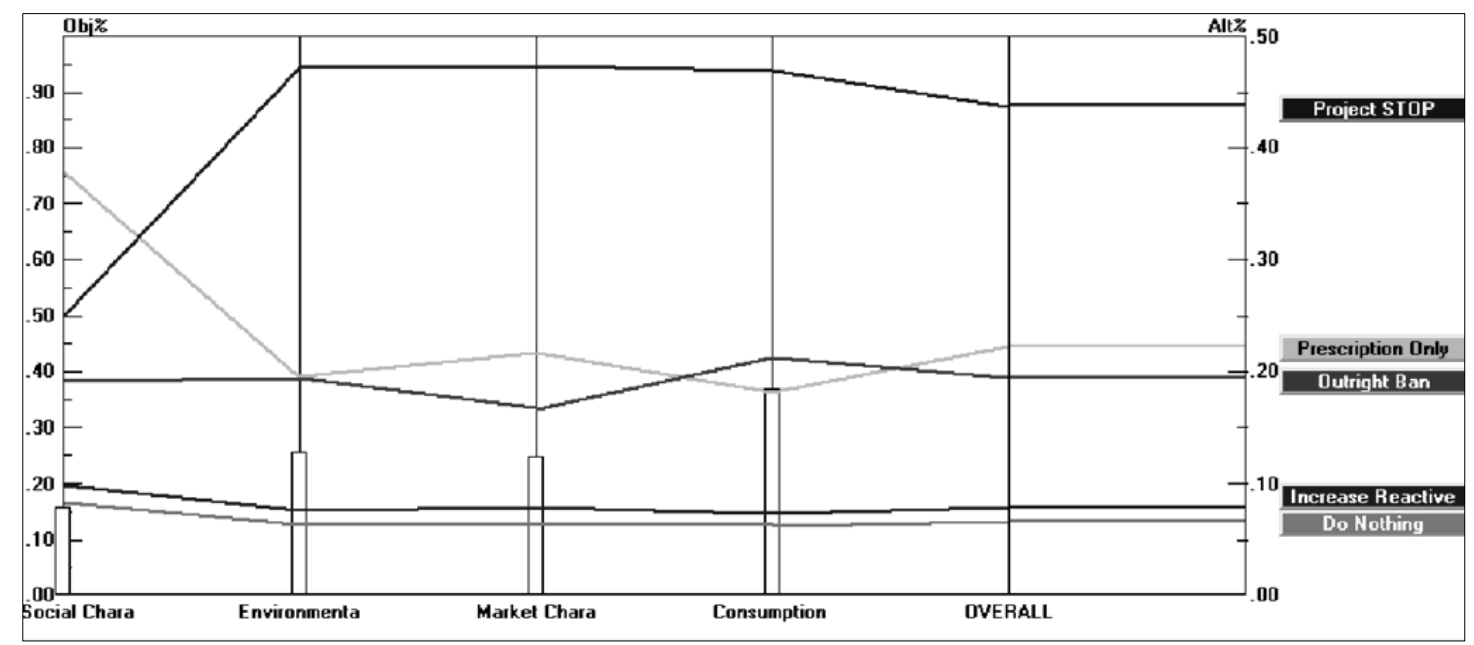


Figure 4: Sensitivity analysis for the characteristic 'social'

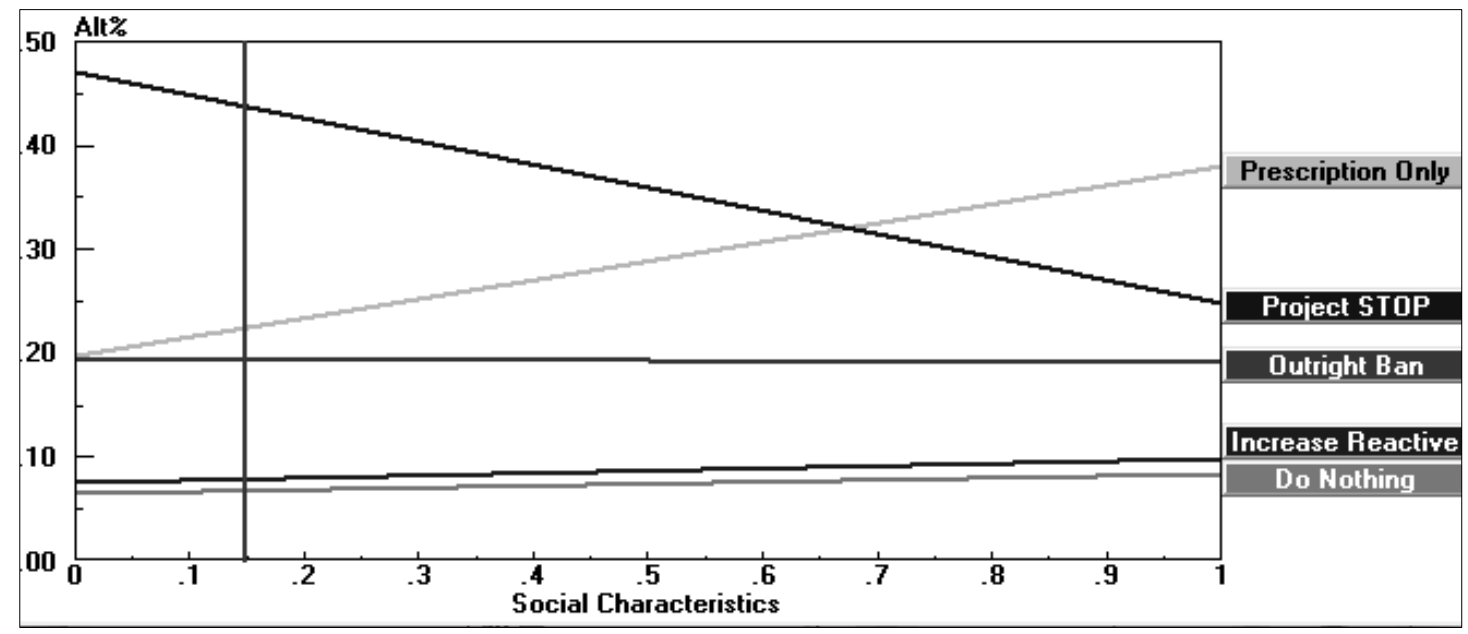


Table 1: Saaty's Comparison scale

\begin{tabular}{|c|c|c|}
\hline Intensity of Importance & Definition & Explanation \\
\hline 1 & Equal importance & $\begin{array}{l}\text { Two elements are of equal } \\
\text { importance }\end{array}$ \\
\hline 3 & Weak importance & $\begin{array}{l}\text { Experience and judgment } \\
\text { slightly favour one element over } \\
\text { another }\end{array}$ \\
\hline 5 & Essential or strong importance & $\begin{array}{l}\text { Experience and judgment } \\
\text { strongly favour one element } \\
\text { over another }\end{array}$ \\
\hline 7 & $\begin{array}{l}\text { Demonstrated or very strong } \\
\text { importance }\end{array}$ & $\begin{array}{l}\text { An element is strongly favoured } \\
\text { and its dominance is } \\
\text { demonstrated in practice }\end{array}$ \\
\hline 9 & Absolute importance & $\begin{array}{l}\text { The evidence favouring one } \\
\text { element over another is of the } \\
\text { highest possible affirmation }\end{array}$ \\
\hline $2,4,6,8$ & Intermediate values & When compromise is needed \\
\hline
\end{tabular}

Adapted from: Saaty (1990). 
Table 2: Example of Pairwise Comparisons of Objectives $\left(q_{1}, q_{2}, q_{3}\right)$

\begin{tabular}{cccc}
\hline & $q_{1}$ & $q_{2}$ & $q_{3}$ \\
\hline$q_{1}$ & 1 & $1 / 3$ & 5 \\
$q_{2}$ & & 1 & 7 \\
$q_{3}$ & & & 1 \\
\hline
\end{tabular}

Adapted from: Saaty (1980). 
Table 3: Example of Completed Matrix Q

\begin{tabular}{cccc}
\hline $\begin{array}{c}\text { Relative } \\
\text { importance }\end{array}$ & $q_{1}$ & $q_{2}$ & $q_{3}$ \\
\hline$q_{1}$ & 1 & $1 / 3$ & 5 \\
$q_{2}$ & 3 & 1 & 7 \\
$q_{3}$ & $1 / 5$ & $1 / 7$ & 1 \\
\hline Sum & $21 / 5$ & $31 / 21$ & 13 \\
\hline
\end{tabular}

Adapted from: Saaty (1980). 
Table 4: Vector of Priorities $Q^{*}$

$Q^{*}=1 / 3\left(\begin{array}{lll}0.24 & 0.23 & 0.38 \\ 0.71 & 0.68 & 0.54 \\ 0.05 & 0.09 & 0.08\end{array}\right)=\left(\begin{array}{l}0.2828 \\ 0.6434 \\ 0.0738\end{array}\right)$ 
Table 5: Combined results of AHP survey for policy option and factors that contribute to the methamphetamine problem

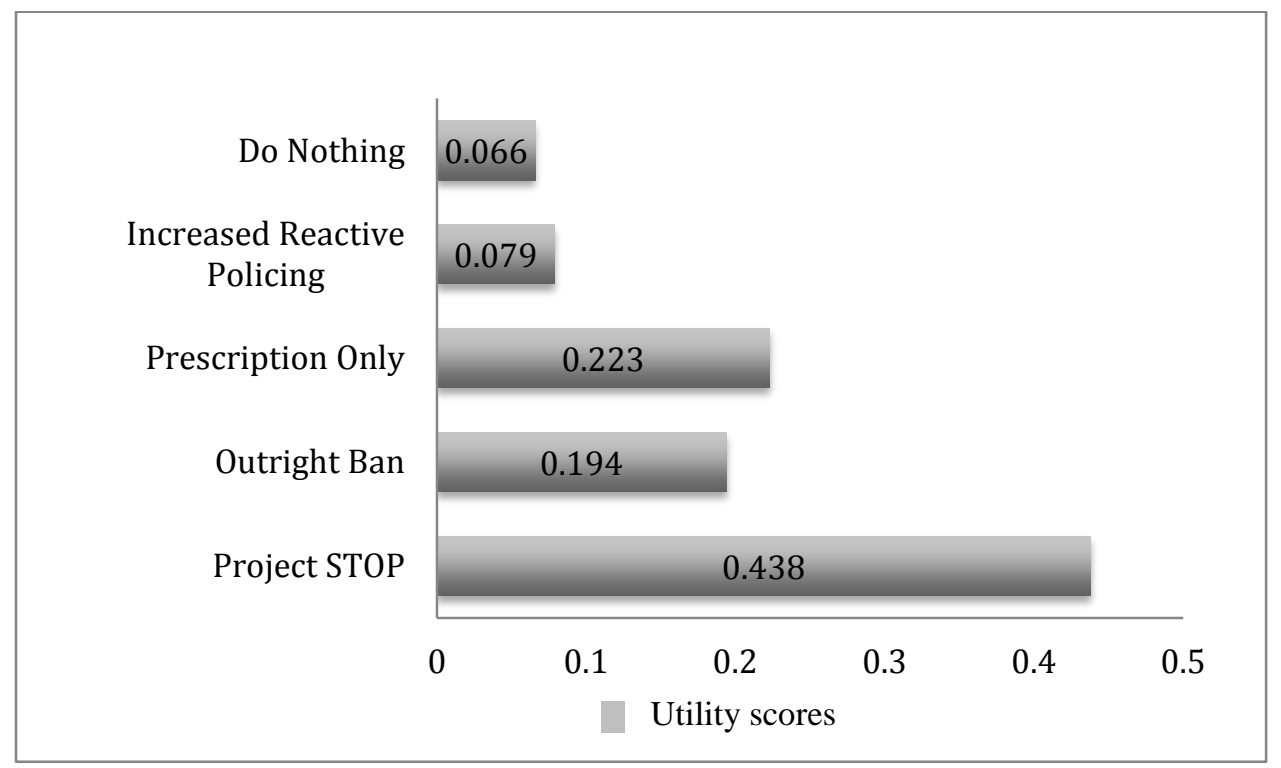


Table 6: AHP results highlighting the characteristics that contribute to the methamphetamine problem

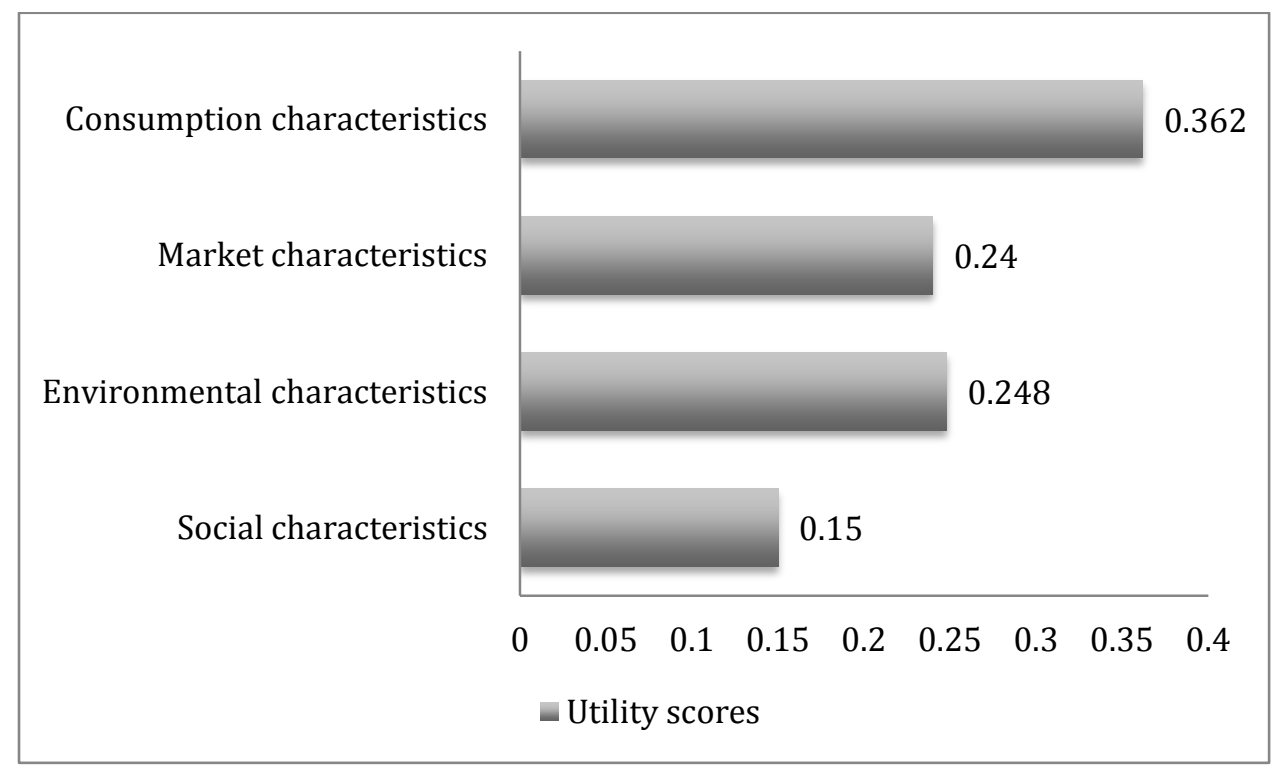

